\title{
Measurement invariance across gender and age groups, validity and reliability of the Chinese version of the short-form supportive care needs survey questionnaire (SCNS-SF34)
}

Edmond Pui Hang Choi ${ }^{1 *}$ (D), Qiuyan Liao ${ }^{2}$, Inda Soong ${ }^{3}$, Karen Kar Loen Chan ${ }^{4}$, Conrad C. Y. Lee ${ }^{5}$, Alice Ng , $^{6}$ Wing Kin Sze ${ }^{6}$, Janice Wing Hang Tsang ${ }^{7}$, Victor Ho Fun Lee ${ }^{7}$ and Wendy Wing Tak Lam,

\begin{abstract}
Background: Despite the wide use of the Short-Form Supportive Care Needs Survey Questionnaire (SCNS-SF34), the measurement invariance of the SCNS-SF34 across the main groups-gender and age—which might be of interest in the application of the instrument has never been confirmed. To provide an accurate assessment tool to evaluate the unmet needs of Chinese cancer patients, the present study aimed to assess the measurement invariance of the SCNS-SF34 across gender and age groups and to assess the validity and reliability of the Chinese version of the SCNS-SF34.

Methods: The SCNS-SF34 was administrated to 1106 Chinese cancer patients. Other instruments included the Memorial Symptom Assessment Scale-Short Form (MSAS-SF), the Short-Form-12 Health Survey version 2 (SF-12 v2) and the Hospital Anxiety and Depression Scale (HADS). Factor structure, internal construct validity, convergent validity, known-group validity and internal consistency were assessed.

Results: Our data fit the original five-factor model. Multi-group confirmatory factor analysis indicated measurement invariance across age and gender groups. The domains of the SCNS-SF34 had moderate correlations with the corresponding domains of the MSAS-SF, the SF-12 V2 and the HADS, which supported convergent validity. Of the 34 items, 33 had an item-total correlation that was corrected for an overlap of $>0.4$ to support the internal construct validity. The SCNS-SF34 aptly differentiated patients by age and gender. The Cronbach's alpha coefficient ranged from 0.64 to 0.87 .
\end{abstract}

Conclusions: We confirm the measurement invariance of the Chinese version of the SCNS-SF34 across gender and age group. It is a valid and reliable tool for evaluating the needs of Chinese patients with cancer.

Keywords: Measurement invariance, Reliability, Unmet need, Validity

\footnotetext{
* Correspondence: h0714919@connect.hku.hk

'School of Nursing, LKS Faculty of Medicine, The University of Hong Kong,

Hong Kong, China

Full list of author information is available at the end of the article
}

(c) The Author(s). 2020 Open Access This article is distributed under the terms of the Creative Commons Attribution 4.0 International License (http://creativecommons.org/licenses/by/4.0/), which permits unrestricted use, distribution, and reproduction in any medium, provided you give appropriate credit to the original author(s) and the source, provide a link to the Creative Commons license, and indicate if changes were made. The Creative Commons Public Domain Dedication waiver (http://creativecommons.org/publicdomain/zero/1.0/) applies to the data made available in this article, unless otherwise stated. 


\section{Background}

Optimising cancer patient-centred care is essential to understand the supportive care needs of cancer patients and to identify any unmet needs [1]. Higher levels of unmet supportive care needs are significantly correlated with more severe levels of psychological distress and poorer health-related quality of life (HRQOL) [2], which leads to higher health service utilisation and costs $[3,4]$. Moreover, information on the unmet needs of cancer patients can instigate improvements in health services [1]. Although the unmet supportive care needs of patients with cancer have been assessed in different populations [1], such information about Chinese cancer populations is still limited even though the Chinese represent $20 \%$ of the global figure. Previous studies on Chinese populations were mainly conducted on patients with colorectal cancer and breast cancer $[5,6]$. That might hinder our understanding of this topic in a broader sense. Thus, there is a need for more research on supportive care needs among Chinese populations.

Several patient-reported outcomes (PROs) have been developed to evaluate the supportive care needs of cancer patients [7]. The Short-Form Supportive Care Needs Survey Questionnaire (SCNS-SF34), which consists of 34 items, is a commonly used instrument. There are 5 domains, including physical and daily living needs (PDL), psychological needs (PSY), patient care and support needs (PCS), health systems and information needs (HSI) and sexuality needs (SEX). The SCNS-SF34 has been validated in different cancer populations, such as China [8], France [9] and Mexico [10]. In Chinese populations, the construct validity and reliability have been established in women with breast cancer in Hong Kong [8] and patients with colorectal cancer in Hong Kong and Taiwan [11] only.

PROs are used to measure latent variables. They can be used to compare groups on some phenomena, such as the level of unmet needs and cancer burden. To be valid for comparison, a PRO must measure identical constructs with the same factor structure across different groups (e.g., gender and age). Evaluating the measurement invariance of PROs across groups of interest can serve the purpose. A good PRO should be able to demonstrate that respondents, across groups of interest, interpret the question items, as well as the underlying construct, in the same way. On the contrary, if measurement invariance cannot be confirmed, mean scores cannot be compared meaningfully. It is because groups or individuals probably interpret the question items differently.

Despite the widespread use of the SCNS-SF34 across different cancer populations, the measurement invariance of the instrument has not been established. A valid comparison of the supportive care needs across age or gender groups requires that the instrument be comparable in these groups. To strengthen and build on the findings of previous validation studies of SCNS-SF34 among cancer patients, the present study aimed to assess the measurement invariance of the SCNS-SF-34 across gender and age groups and to validate the SCNS-SF34 among Chinese cancer patients in Hong Kong by evaluating the psychometric properties.

\section{Methods}

\section{The study sample and setting}

A convenience sample of Chinese patients with cancer was recruited in five public hospitals in Hong Kong. The inclusion criteria were as follows: age $\geq 18$ years, within 6 months of completing primary and adjuvant treatment, and fluency in Chinese language. Patients were excluded if they had hearing impairment, refused to join, or were too ill to give informed consent or complete the questionnaires. Patients who consented to join the study were asked to complete a structured questionnaire. A cancer diagnosis and the stages of cancer were retrieved from each patient's medical record. Ethics approval (UW10-203) was obtained. Written informed consent was obtained for each participant.

\section{Study instruments SCNS-SF34}

The Chinese version of the SCNS-SF34 was used in the present study [12]. The SCNS-SF34 consists of five question areas: the 5-item PDL, the 10-item PSY, the 5-item PCS, the 11-item HSI and the 3-item SEX. Patients rated the intensity of each specified need over the past month on a 5 -point Likert scale $(1=$ no need, not applicable; $2=$ no need, satisfied; $3=$ low need; $4=$ moderate need; 5 = high need). It is recommended to use a Likert summated scale by summing the individual items within a domain (item 1 to 5 for the PDL; item 6 to 14, \& item 17 for the PSY; item 15, 16 and 31 for the SEX; item 18 to 22 for the PCS; item 23 to 30 and item 32 to 34 for the HSI). Domain scores were converted to standardised Likert summated scores, ranging from 0 to 100, with higher scores indicating a higher perceived unmet care need [13].

\section{Memorial symptom assessment scale-short form (MSAS-SF)}

The Chinese version of the MSAS-SF was used to measure symptom distress. The first part of the instrument measures distress regarding 28 physical and psychological symptoms during the past week. Patients rate the level of distress of each symptom on a 5-point Likert scale. The second part of the instrument measures the frequency of four psychological symptoms during the past week. Patients rate the frequency of each symptom on a 4-point Likert scale. Only the Physical Symptoms 
Subscale (MSAS-PHYS) and the Psychological Symptoms Subscale (MSAS-PSYCH) were used in the present study. The subscale scores range from zero to four, with higher scores indicating a higher level of distress. The instrument has been validated in cancer patients in Hong Kong [14].

\section{Short-Form-12 health survey version 2 (SF-12 v2)}

The Hong Kong Chinese version of the SF-12 v2 was used in this study to measure generic HRQOL during the previous 4 weeks. It consists of scores from the Physical Component Summary and the Mental Component Summary (MCS), with higher scores indicating better generic HRQOL. The psychometric properties of the Chinese version of the SF-12 v2 have been confirmed [15]. It has been widely used for patients with different types of cancer, such as prostate [16].

\section{Hospital anxiety and depression scale (HADS)}

The Chinese version of the HADS was used in this study. It consists of two subscales, which measure depression and anxiety symptoms during the previous week [17]. Each subscale has seven questions, and patients need to indicate the severity of each symptom on a four-point Likert scale. The score of each item in each subscale is added to generate a total score, ranging from 0 to 21 . Higher scores imply more severe anxiety or depression. A review article suggested that the HADS had adequate psychometric properties to assess the severity of symptoms in different populations [18]. Additionally, the HADS has been validated in Hong Kong [19].

\section{Statistical analysis}

\section{Factor structure and measurement invariance}

First, confirmatory factor analysis (CFA) was used to evaluate the factor structure of the SCNS-SF34. We fit our data to the original five-factor model of the SCNSSF34 [20]. The CFA was tested using the weighted least squares mean and variance that accounted for the categorical nature of the items. Criteria for an acceptable fit were a root mean square error of approximation (RMSEA) of $<0.06$, a comparative fit index (CFI) and a Tucker-Lewis index (TLI) of $\geq 0.90[21,22]$.

Second, the following steps were conducted with weighted least squares estimator using the theta parameterisation to evaluate the measurement invariance across gender and age groups [23].

1. Thresholds and factor loadings were free across groups. Residual variances were fixed at one in all groups, and factor means were fixed at zero in all groups. It was the least constrained model.

2. Thresholds and factor loadings were constrained to be equal across groups. As a default, residual variances were fixed at one in the first group and freely estimated in the second group. Factor means were fixed at zero in the first group and freely estimated in the second group. It was the more constrained model.

Model difference testing was conducted using the "DIFFTEST" provided by Mplus, which calculated the chi-square difference between the least and more constrained models based on scaling correction factors. If the chi-square difference value was not statistically significant, it indicated that constraining the parameters of the nested model did not significantly worsen the fit of the model, supporting the measurement invariance of the parameters constrained to be equal in the nested model.

\section{Internal construct validity and convergent validity}

The item-total correlation that was corrected for overlap was used to evaluate internal construct validity. A correlation coefficient of $\geq 0.4$ was used as the threshold for adequate correlation [24]. Convergent validity was assessed using Pearson's correlations between the SCNSSF34, HADS, MSAS-SF and SF-12 v2 scores. It was first hypothesised that the PSY domain of the SCNS-SF34 would have a moderate correlation with the HADS, MSAS-PSYCH and SF-12 v2 MCS scores because they specifically measure psychological constructs. It was also hypothesised that the PDL domain of the SCNS-SF34 would have a moderate correlation with the MSASPHYS and SF-12 v2 Physical Component Summary scores because they specifically measure constructs that are related to physical aspects.

\section{Known-group validity}

Four known-group comparisons were carried out using an independent t-test. We first compared the SCNSSF34 scores between participants $\leq 60$ and $>60$ years old. It was hypothesised that younger patients would report higher levels of unmet needs than would older patients [25]. We then compared the SCNS-SF34 scores by gender. Cohen's D effect sizes were calculated as either trivial $(<0.2)$, small $(\geq 0.2$ and $<0.5)$, moderate $(\geq 0.5$ and $<0.8)$ or large $(\geq 0.8)[26]$.

\section{Reliability}

The internal consistency of the SCNS-SF34 was assessed by Cronbach's alpha, and a coefficient of $\geq 0.7$ was considered good [27].

Mplus (version 7.4 for Windows) and SPSS (version 23 for Windows) were used. 


\section{Results}

\section{Participants' characteristics}

In total, 1106 cancer patients were included in the analysis. Six hundred and fifty- five participants (59.22\%) were female. The mean age was 55.41 years (standard deviation [SD]: 11.91). Eight hundred and twenty-eight participants $(74.86 \%)$ were either married or cohabitating. More than half the study sample had received either secondary or tertiary education. $30.74 \%$ of the participants had a full-time job. More than half of the study sample had a total family income that was $\leq$ HKD\$20, 000. The most common type of cancer diagnosis was breast cancer (34.63\%), followed by head and neck cancer $(19.71 \%)$, colorectal cancer $(12.03 \%)$ and gynaecological cancer (11.66\%). In addition, 224, 366, 332 and 81 participants were diagnosed with stages I, II, III and IV cancers, respectively. These results are shown in Table 1.

The descriptive statistics of the SCNS-SF34 are shown in Table 2. The mean score was 14.75 (SD: 14.49) for the PDL domain, 12.42 (SD: 13.96) for the PSY domain, 5.29 (SD: 11.46) for the SEX domain, 22.97 (SD: 20.46) for the PCS domain and 34.56 (SD: 21.46) for the HSI domain.

\section{Factor structure and measurement invariance across gender and age groups}

The original 5-factor SCNS-SF34 model was tested by confirmatory factor analysis. The goodness-of-fit indices indicted that our data fitted the original 5-factor model (RMSEA: 0.047; CFI: 0.952; TLI: 0.947). Regarding the measurement invariance across genders, the chi-square test for difference testing was 120.256 with 111 degrees of freedom, $p$-value $=0.2581$. The statistical insignificance of the test supported the assumption of measurement invariance across gender groups. Regarding the measurement invariance across age groups, the chisquare test for difference testing was 113.049 with 111 degrees of freedom, $p$-value $=0.4280$. The statistical insignificance of the test supported the assumption of measurement invariance across age groups. These results are shown in Table 3. The figures of the models are shown in Appendix 1.

\section{Internal construct validity and convergent validity}

The internal construct validity and convergent validity of the SCNS-SF34 were supported. The results of the analyses that evaluated internal construct validity are shown in Table 2. The item-total correlations that were corrected for overlap were $>0.4$ for all items, except for item 31 (0.30). The results of the convergent validity are shown in Table 4. In line with our hypotheses, the PSY domain score had a moderate correlation with the scores of the HADS anxiety subscale $(\mathrm{r}=0.65, p$-value $<0.01)$, the HADS depression subscale $(\mathrm{r}=0.54, p$-value $<0.01)$, the MSAS psychological symptom subscale $(\mathrm{r}=0.64, p$ value $<0.01)$ and the SF-12 v2 MCS $(\mathrm{r}=-0.46, p$-value $<0.01$ ). Similarly, the PDL domain score also had a moderate correlation with the MSAS physical symptom subscale $(\mathrm{r}=0.53, p$-value $<0.01)$ as well as the SF-12 v2 Physical Component Summary $(\mathrm{r}=-0.48, p$-value < 0.01). Other domain scores of the SCNS-SF34 only had a weak correlation with the scores of the HADS, the MASA and the SF-12 v2. The results about convergent validity are shown in Table 4.

\section{Known-group validity}

The results of the analyses that examined the sensitivity of the SCNS-SF34 are shown in Table 5. We first compared the SCNS-SF34 domain scores of patients who were aged $\leq 60$ and $>60$ years via an independent t-test. Statistically significant differences were found between these groups for all domains. The Cohen's D effect size was 0.28 for the PDL domain, 0.45 for the PSY domain, 0.35 for the SEX domain, 0.41 for the PCS domain and 0.40 for the HIS domain. Second, we compared the SCNS-SF34 domain scores by gender. Statistically significant differences were found in the PSY domain (effect size: 0.33), the PCS domain (effect size: 0.38) and the HSI domain (effect size 0.32).

\section{Reliability}

The value of the Cronbach's alpha coefficient was 0.74 for the PDL subscale, 0.87 for the PSY subscale, 0.64 for the SEX subscale, 0.76 for the PCS subscale and 0.85 for the HSI subscale. Table 2 shows the results.

\section{Discussion}

To the best of our knowledge, this was the first study to specifically evaluate and confirm the measurement invariance of the SCNS-SF34 across the main groups that might be of interest in the application of the instrument: gender and age. Measurement invariance is a prerequisite for making quantitative comparisons. In other words, confirmation of measurement invariance permits meaningful group comparisons. Our study found that the measurement model of the SCNS-SF34 as a patientreported outcome to measure supportive care needs among cancer patients is comparable across gender and age groups.

The study also provided robust evidence in terms of validity and reliability to support the use of this instrument to evaluate the unmet supportive care needs in Chinese populations. The convergent validity of the Chinese version of the SCNS-SF34 was demonstrated in the present study. In line with our hypotheses, the PSY domain of the SCNS-SF34 had a strong-to-moderate correlation with the HADS, the MSAS-PSYCH and the 
Table 1 Socio-demographic and clinical characteristics

\begin{tabular}{|c|c|c|c|c|c|}
\hline Mean age (SD), $n=1103$ & $55.41(11.91)$ & Type of cancer, n (\%) & & Mean score of study outcomes (SD) & \\
\hline Gender & & Breast cancer & $383(34.63)$ & SCNS-SF34 & \\
\hline Male & $451(40.78)$ & Colorectal cancer & $133(12.03)$ & Physical and daily living needs (PDL), $n=1100$ & $14.75(14.49)$ \\
\hline Female & $655(59.22)$ & Gynaecological cancer & 129(11.66) & Psychological needs (PSY), $n=1084$ & $12.42(13.96)$ \\
\hline Marital status, n (\%) & & Prostate cancer & $75(6.78)$ & Sexual need (SEX), n=1102 & $5.29(11.46)$ \\
\hline Single & $120(10.85)$ & Lung cancer & $72(6.51)$ & Patient care and support needs (PCS), n=1098 & $22.97(20.46)$ \\
\hline Married/cohabited & $828(74.86)$ & Head and neck cancer & $218(19.71)$ & Health systems and information needs (HIS), n= 1086 & $34.56(21.46)$ \\
\hline Divorced/separated & $87(7.87)$ & Leukaemia/lymphoma & $25(2.26)$ & $S F-12$ v2 & \\
\hline Widowed & $68(6.15)$ & Sarcoma & $6(0.54)$ & Physical Component Summary (PCS), $n=1068$ & $46.68(8.45)$ \\
\hline Missing & $3(0.27)$ & Hepatobiliary cancer & $8(0.72)$ & Mental Component Summary (MCS), n=1068 & $44.82(10.74)$ \\
\hline Education level, n (\%) & & Gastric cancer & $21(1.30)$ & MSAS-SF & \\
\hline No formal education & $60(5.42)$ & Oesophageal cancer & $15(1.36)$ & Physical Symptom subscale, n=1096 & $0.47(0.52)$ \\
\hline Primary education & $318(28.75)$ & Others & $21(1.90)$ & Psychological Symptom subscale, $n=1092$ & $0.52(0.69)$ \\
\hline Secondary education & $577(52.17)$ & Stage of disease, $n(\%)$ & & HADS & \\
\hline Tertiary education & $149(13.47)$ & Stage I & $224(20.25)$ & Anxiety level, $n=1100$ & $2.32(2.97)$ \\
\hline Missing & $2(0.18)$ & Stage II & 366 (33.09) & Depression level, n=1098 & $3.06(3.27)$ \\
\hline Occupation, n (\%) & & Stage III & $332(30.02)$ & & \\
\hline Full-time & $340(30.74)$ & Stage IV & $81(7.32)$ & & \\
\hline Part-time & $48(4.34)$ & Missing & $103(9.31)$ & & \\
\hline Retired & $291(26.31)$ & & & & \\
\hline Housewife & $128(11.57)$ & & & & \\
\hline $\begin{array}{l}\text { Unemployed } \\
\text { (before diagnosis } \\
\text { of cancer) }\end{array}$ & $28(2.53)$ & & & & \\
\hline $\begin{array}{l}\text { Unemployed } \\
\text { (since diagnosis } \\
\text { of cancer) }\end{array}$ & $268(24.23)$ & & & & \\
\hline Missing & $3(0.27)$ & & & & \\
\hline Monthly household incor & ne, n (\%) & & & & \\
\hline$\leq \operatorname{HKD} \$ 20,000$ & $658(59.49)$ & & & & \\
\hline$>\operatorname{HKD} \$ 20,001$ & $380(34.36)$ & & & & \\
\hline Missing & $68(6.15)$ & & & & \\
\hline
\end{tabular}

Abbreviation SD: Standard deviation; SCNS-SF34: the Short-Form Supportive Care Needs Survey Questionnaire; PDL: Physical and daily living needs; PSY: Psychological needs; SEX: Sexual need; PCS: Patient care and support needs: HIS: Health systems and information needs: SF-12 v2: the Short-Form-12 Health Survey version 2; MSAS-SF: the Memorial Symptom Assessment Scale-Short Form; HADS: the Hospital Anxiety and Depression Scale

scores of the SF-12 v2 MCSs. The PDL domain of the SCNS-SF34 had a moderate correlation with the MSASPHYS and the SF-12 v2 Physical Component Summary scores. These findings were similar to those found in Chinese patients with colorectal cancer [11], Chinese patients with breast cancer [8], Mexican patients with cancer [10], etc. Similar to previous studies, we also observed moderate correlations between the PDL domain and other psychological outcomes, such as the HADS, the MSAS-PSYCH and the SF-12 v2 MCS, which implied that unmet physical and daily living needs would lead to psychological distress. Further longitudinal studies are needed to confirm this temporal relationship. As expected, only weak correlations were found between the other domains of the SCNS-SF34 (the SEX, the PCS and the HIS) and other study outcomes because they measure different concepts.

The SCNS-SF34 was able to differentiate between age groups in all domains. We found that young patients had a higher level of unmet care needs in all five domains. Notably, other literature has also suggested that older cancer patients tend to have lower levels of unmet needs than do their younger counterparts [25, 28]. Possible explanations for the lower unmet needs among older patients include the following. A stoic attitude of older people has been found to account for age-related differences in the prevalence of physical symptoms [29]. It has been suggested that older people are inclined to 


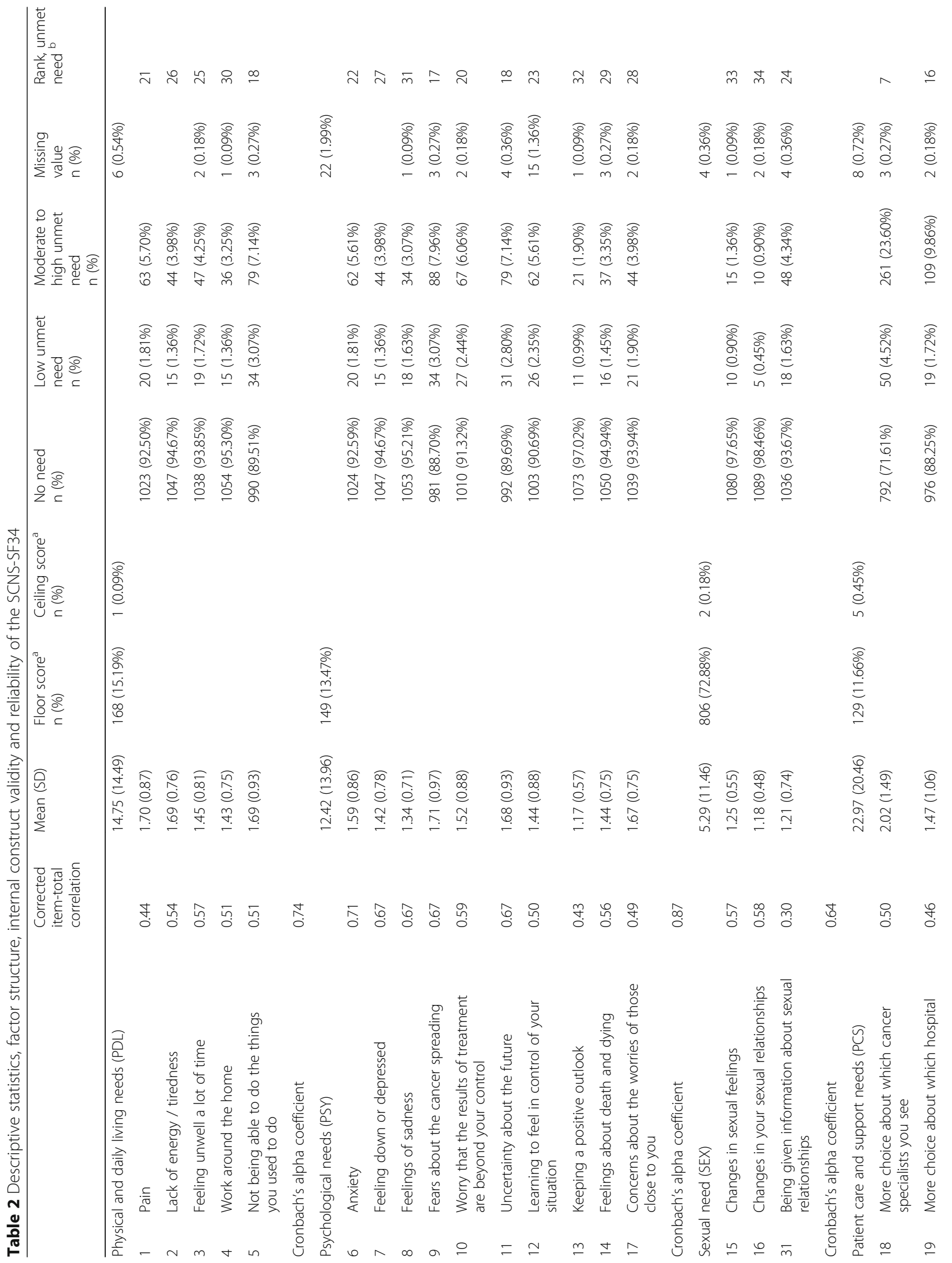




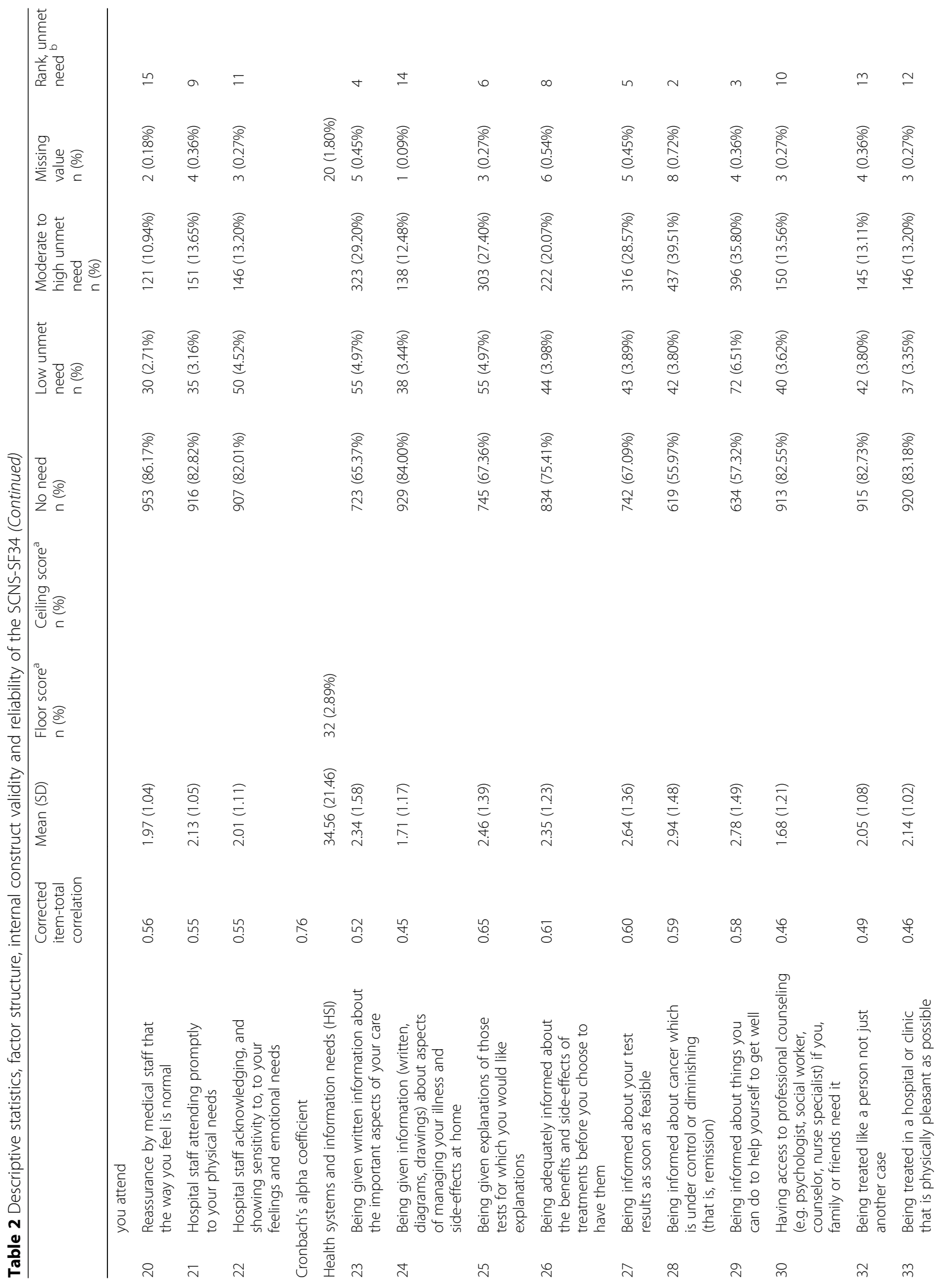




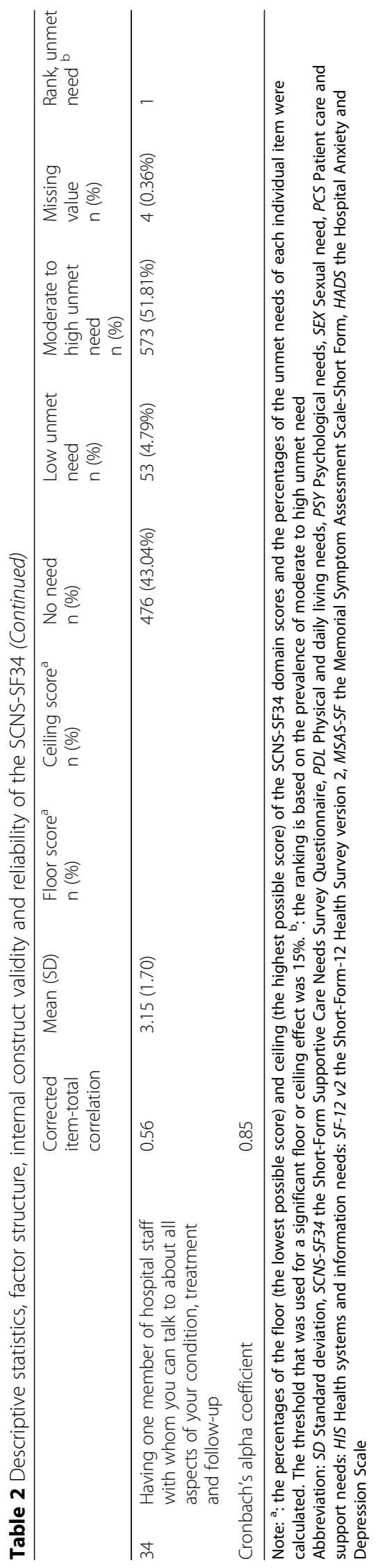


Table 3 Measurement invariance of the SCNS-34

\begin{tabular}{|c|c|c|c|c|c|c|c|}
\hline \multicolumn{2}{|c|}{ Chi-square value of model fit } & \multirow{2}{*}{$\begin{array}{l}\text { DF } \\
517\end{array}$} & \multirow{2}{*}{$\frac{p \text {-value }}{<0.001}$} & \multirow{2}{*}{$\frac{\mathrm{CF}^{\mathrm{d}}}{0.952}$} & \multirow{2}{*}{$\frac{\mathrm{TLI}^{\mathrm{d}}}{0.947}$} & \multirow{2}{*}{$\frac{\text { RMSEA }^{d}}{0.047}$} & \multirow{2}{*}{$\frac{90 \% \mathrm{Cl}}{0.044,0.049}$} \\
\hline Baseline model & 1762.722 & & & & & & \\
\hline \multicolumn{8}{|c|}{ Measurement invariance across gender } \\
\hline Model $1^{\text {a }}$ & 2240.351 & 1049 & $<0.001$ & 0.950 & 0.946 & 0.045 & $0.043,0.048$ \\
\hline Model $2^{b}$ & 2246.337 & 1160 & $<0.001$ & 0.954 & 0.956 & 0.041 & $0.039,0.04$ \\
\hline
\end{tabular}

Chi-Square difference test for measurement invariance across gender

$\begin{array}{lll}\text { Chi-square value } & \text { DF } & \boldsymbol{p}_{\text {-value }}{ }^{c} \\ 120.256 & 111 & 0.2581\end{array}$

Measurement invariance across age groups

\begin{tabular}{|c|c|c|c|c|c|c|c|}
\hline & Chi-square value of model fit & DF & $p$-value & $\mathrm{CFI}$ & TLI & RMSEA & $90 \% \mathrm{Cl}$ \\
\hline Model $1^{\text {a }}$ & 2172.758 & 1049 & $<0.001$ & 0.948 & 0.944 & 0.045 & $0.042,0.048$ \\
\hline Model $2^{b}$ & 2226.458 & 1160 & $<0.001$ & 0.953 & 0.954 & 0.041 & $0.038,0.043$ \\
\hline
\end{tabular}

Chi-Square difference test for measurement invariance across age groups

$\begin{array}{lll}\text { Chi-square value } & \text { DF } & \boldsymbol{p}_{\text {-value }}{ }^{\mathbf{c}} \\ 113.049 & 111 & 0.4280\end{array}$

Note: ${ }^{\mathrm{a}}$ Model 1: it was the least constrained model. Thresholds and factor loadings were free across groups. Residual variances were fixed at one in all groups and factor means were fixed at zero in all groups. ${ }^{b}$ Model 2 : it was the more constrained model. Thresholds and factor loadings were constrained to be equal across groups. As default, residual variances were fixed at one in the first group and freely estimated in the second group. Factor means were fixed at zero in the first group and freely estimated in the second group. ${ }^{c}$ : the chi-square difference value is not significant. It indicated that constraining the parameters of the nested model did not significantly worsen the fit of the model. Our result indicted measurement invariance. ${ }^{\mathrm{d}}$ : Criteria for an acceptable fit were a root mean square error of approximation (RMSEA) of $<0.06$, and a comparative fit index (CFI) and Tucker-Lewis index (TLI) of $\geq 0.90$

Abbreviation: DF Degree of freedom, CFI Comparative fit index, TLI Tucker-Lewis Index, SRMR Standardised root mean square residual, RMSEA Root mean square error of approximation, $\mathrm{Cl}$ Confidence interval

keep their needs private because they believe that they should be able to manage by themselves [30]. Older people tend to underreport their needs because they do not want to burden their families and caregivers [31]. They are concerned that they will become dependent if they report problems [32]. They want to minimise their problems and needs to avoid negative stereotypes about ageing [33]. However, very few studies focus on the commonly held attitudes and beliefs towards the expression of unmet needs by older patients, warranting more studies in this area.

The SCNS-SF34 differentiated between gender groups in four out of five domains. We found that female patients reported a higher level of unmet needs. From the psychooncological perspective, research findings on the gender difference in cancer-related symptoms, impairment and adjustment are mixed. A validation study of German cancer patients found that female patients expressed a higher amount of unmet psychological and physical needs but a lower amount of unmet sexuality need than their male counterparts [34]. A study in Australia demonstrated that female patients reported a higher amount of unmet psychological needs than male patients [35]. Previous studies found that compared with male cancer patients, female patients reported more physical symptoms, such as nausea, vomiting and fatigue [36, 37].

Table 4 Convergent validity of the SCNS-34

\begin{tabular}{|c|c|c|c|c|c|c|}
\hline & HADS Anxiety & HADS Depression & MSAS-PHY & MSAS-PSYC & SF-12 v2 PCS & $\mathrm{SF}-12$ v2 MCS \\
\hline Physical and daily living needs (PDL) & $0.39^{* *}$ & $0.45^{* *}$ & $0.53^{* *}$ & $0.44^{* *}$ & $-0.48^{* *}$ & $-0.39^{* *}$ \\
\hline Psychological needs (PSY) & $0.65^{* *}$ & $0.54^{* *}$ & $0.45^{* *}$ & $0.64^{* *}$ & $-0.33^{* *}$ & $-0.46^{* *}$ \\
\hline Sexual need (SEX) & $0.14^{* *}$ & $0.17^{* *}$ & $0.18^{* *}$ & $0.19^{* *}$ & $-0.15^{* *}$ & $-0.11^{* *}$ \\
\hline Patient care and support needs (PCS) & $0.37^{* *}$ & $0.28^{* *}$ & $0.23^{* *}$ & $0.37^{* *}$ & $-0.20^{* *}$ & $-0.24^{* *}$ \\
\hline Health systems and information needs (HSI) & $0.35^{* *}$ & $0.26^{* *}$ & $0.25^{* *}$ & $0.35^{* *}$ & $-0.20^{* *}$ & $-0.23^{* *}$ \\
\hline
\end{tabular}

Note: ** Pearson correlation $(p<0.01)$

Abbreviation: SD SCNS-SF34: the Short-Form Supportive Care Needs Survey Questionnaire, PDL Physical and daily living needs, PSY Psychological needs, SEX Sexual need, PCS Patient care and support needs, HIS Health systems and information needs, SF-12 v2 PCS Physical Component Summary of the Short-Form-12 Health Survey version 2, SF-12 v2 MCS Mental Component Summary of the Short-Form-12 Health Survey version 2, MSAS-PHYS Physical Symptoms Subscale of the Memorial Symptom Assessment Scale-Short Form, MSAS-PSYCH Psychological Symptoms Subscale of the Memorial Symptom Assessment Scale-Short Form, HADS the Hospital Anxiety and Depression Scale 
Table 5 Known-group comparison of the SCNS-34

\begin{tabular}{|c|c|c|c|c|c|c|}
\hline & \multicolumn{2}{|c|}{60 years or below } & \multicolumn{2}{|c|}{$>60$ years } & \multirow[t]{2}{*}{ Cohen's D effect Size } & \multirow[t]{2}{*}{$P$-value } \\
\hline & $\bar{n}$ & Mean (SD) & $\bar{n}$ & Mean (SD) & & \\
\hline Physical and daily living needs (PDL) & 732 & $16.08(15.03)$ & 365 & $12.12(13.01)$ & 0.28 & $<0.001$ \\
\hline Psychological needs (PSY) & 723 & $14.36(14.96)$ & 359 & $8.49(10.73)$ & 0.45 & $<0.001$ \\
\hline Sexual need (SEX) & 735 & $6.56(12.06)$ & 365 & $2.74(9.71)$ & 0.35 & $<0.001$ \\
\hline Patient care and support needs (PCS) & 734 & $25.66(20.78)$ & 362 & $17.49(18.71)$ & 0.41 & $<0.001$ \\
\hline \multirow[t]{3}{*}{ Health systems and information needs (HSI) } & 727 & $37.35(20.95)$ & 357 & $28.93(21.46)$ & 0.40 & $<0.001$ \\
\hline & \multicolumn{2}{|c|}{ Males } & \multicolumn{2}{|c|}{ Females } & Cohen's D effect Size & $P$-value \\
\hline & $\mathrm{n}$ & Mean (SD) & $\mathrm{n}$ & Mean (SD) & & \\
\hline Physical and daily living needs (PDL) & 450 & $13.51(13.80)$ & 650 & $15.61(14.30)$ & 0.15 & 0.02 \\
\hline Psychological needs (PSY) & 444 & $9.76(11.57)$ & 640 & $14.27(15.14)$ & 0.33 & $<0.001$ \\
\hline Sexual need (SEX) & 449 & $5.44(11.33)$ & 653 & $5.18(11.56)$ & 0.02 & 0.69 \\
\hline Patient care and support needs (PCS) & 447 & $18.50(18.69)$ & 651 & $26.04(21.07)$ & 0.38 & $<0.001$ \\
\hline Health systems and information needs (HSI) & 443 & $30.53(20.93)$ & 643 & $37.35(21.40)$ & 0.32 & $<0.001$ \\
\hline
\end{tabular}

Abbreviation: SD Standard deviation, SCNS-SF34 the Short-Form Supportive Care Needs Survey Questionnaire, PDL Physical and daily living needs, PSY Psychological needs, SEX Sexual need, PCS Patient care and support needs, HIS Health systems and information needs

Moreover, a study of more than 10,000 cancer patients found a higher rate of anxiety and depression in women than in men [38]. In contrast, some studies have found that men experience more cancer-related impairments. For example, in a study of patients with colorectal cancer in Israel, it was found that, compared with women, men reported a higher level of psychological distress, intrusive thoughts, avoidance and feelings of helplessness [39]. Another study on cancer patients in the United States found that men had significantly more cancerrelated impairments, fewer social resources and more limitations in activities of daily living than did women [40]. Some theories, such as the transactional theory of stress and coping [41], can explain the gender difference in cancer burden.

A meta-analysis of 119 studies found that women experienced more stressors than did men [42]. The analysis also found that women appraised their stressors to be more severe than men did [42]. The gender difference in cancer-related distress might reflect the gender difference in distress in broader adult populations found in the meta-analysis [42]. These findings have some important implications. For example, given the gender difference in cancer-related symptoms, impairment and adjustments, it is likely that supportive care needs, preferences and expectations regarding cancer care are different between men and women [43]. Therefore, supportive care for cancer patients should be genderspecific to further improve cancer patient-centred care and to narrow the gender disparity in the cancer burden [40, 43]. In addition, research findings on women with cancer cannot be generalisable to men with cancer and vice versa.
The Chinese version of the SCNS-SF34 demonstrated good internal consistency, with a Cronbach's alpha coefficient of $>0.7$ for four domains. The Cronbach's alpha coefficient of the SEX domain was just short of 0.7 in the current study sample, which is acceptable [44]. Notably, a previous study on Chinese patients with colorectal cancer obtained an even lower Cronbach's alpha coefficient (0.534) [11]. One possible explanation is that item 31-'Being given information about sexual relationships'-had a weak correlation with the other items within the same domain. Furthermore, it should be noted that the Cronbach's alpha coefficient is also affected by the number of test items (i.e., if the number of test items is too small, it will underestimate the reliability).

The current study also serves as the foundation for further understanding of how Chinese patients with cancer prioritise supportive care. Eight of the top ten unmet needs were related to the HSI domain. Indeed, this finding is not unique to our study sample. A systematic review of studies on Chinese populations found that the HSI is the most commonly reported needs, with a pooled prevalence of $43.01 \%$ [45]. Similar to previous studies in Hong Kong $[6,8]$, the primary unmet need in the present study was having one member of the hospital staff with whom to talk about all aspects of one's condition, treatment and follow-up. In Hong Kong public hospitals, patients cannot choose a doctor; they are randomly assigned to the next available doctor on the oncology team. Thus, our findings urge improvements in the continuity of cancer care in Hong Kong.

Some limitations of the present study should be noted. Given the cross-sectional nature of the analysis, we were 
unable to determine test-retest reliability and the responsiveness of the instrument. Also, all patients were recruited within 6 months after they completed the treatment. But that should not matter much since the findings from the current study are comparable to the one reported in previous local studies. In addition, all patients were recruited from government-funded public hospitals. Our study findings might therefore not be generalisable to private settings, where patients are more likely to have a higher socioeconomic status and better health-seeking behaviours. There might be differences in unmet needs. However, public hospitals provide cancer care for the majority of cancer patients in Hong Kong.

\section{Conclusion}

In the present study, we evaluated the factor structure, measurement invariance, internal construct validity, convergent validity, known-group validity and internal consistency of the SCNS-SF34 among Chinese patients with cancer. Our findings suggest that the SCNS-SF34 is a valid and reliable instrument to evaluate and understand the unmet needs of Chinese cancer patients. To provide patient-centred care for cancer patients, clinicians should consider using this instrument in routine clinical practice.

\section{Supplementary information}

Supplementary information accompanies this paper at https://doi.org/10. 1186/s12955-020-01289-0.

Additional file 1. Measurement invariance across gender and age groups.

\section{Abbreviations \\ CFA: Confirmatory factor analysis; CFI: Comparative fit index; HADS: Hospital Anxiety and Depression Scale; HRQOL: Health-related quality of life; HSI: Health systems and information needs; MSAS-SF: Memorial Symptom Assessment Scale-Short Form; PCS: Patient care and support needs; PDL: Physical and daily living needs; PROs: Patient-reported outcomes; PSY: Psychological needs; RMSEA: Root mean square error of approximation; SCNS-SF34: Short-Form Supportive Care Needs Survey Questionnaire; SD: Standard deviation; SEX: Sexuality needs; SF-12 v2: Short-Form-12 Health Survey version 2; TLI: Tucker-Lewis index}

\section{Acknowledgments}

We are grateful for the time given by our participants to contribute to this research. Funding for this study was provided by a generous grant from the Hong Kong Cancer Fund.

\footnotetext{
Authors' contributions

EPHC: data analysis, interpretation of data, writing the manuscript; QL: data analysis, interpretation of data, revising the manuscript; IS: design of the work, the acquisition of data; KKLC: design of the work, the acquisition of data; CCYL: design of the work, the acquisition of data; AN: design of the work, the acquisition of data; WKS: design of the work, the acquisition of data; JWHT: design of the work, the acquisition of data; VHFL: design of the work, the acquisition of data; WWTL: design of the work, interpretation of data, revising the manuscript. All authors have approved the submitted version.
}

Funding

Funding for this study was provided by a generous grant from the Hong Kong Cancer Fund.

\section{Availability of data and materials}

The datasets generated and/or analysed during the current study are not publicly available because it contains personal data but are available from the corresponding author on reasonable request.

\section{Ethics approval and consent to participate}

Ethics approval was obtained from Institutional Review Board of the University of Hong Kong/Hospital Authority Hong Kong West Cluster (HKU/ HA HKW IRB). Reference: (UW10-203).

Written informed consent was obtained for each participant.

\section{Consent for publication}

Not applicable.

\section{Competing interests}

The authors declare that they have no competing interests.

\section{Author details}

${ }^{1}$ School of Nursing, LKS Faculty of Medicine, The University of Hong Kong, Hong Kong, China. ${ }^{2}$ School of Public Health, LKS Faculty of Medicine, The University of Hong Kong, Hong Kong, China. ${ }^{3}$ Department of Clinical Oncology, Pamela Youde Nethersole Eastern Hospital, Chai Wan, Hong Kong, China. ${ }^{4}$ Department of Obstetrics \& Gynaecology, Queen Mary Hospital, Hong Kong, China. ${ }^{5}$ Department of Clinical Oncology, Princess Margaret Hospital, Hong Kong, China. ${ }^{6}$ Department of Clinical Oncology, Tuen Mun Hospital, Hong Kong, China. ${ }^{7}$ Department of Clinical Oncology, Queen Mary Hospital, Hong Kong, China. ${ }^{8}$ Jockey Club Institute of Cancer Care, Centre for Psycho-Oncology Research \& Training, Hong Kong, China. ${ }^{9}$ School of Public Health, The University of Hong Kong, Hong Kong, China.

Received: 24 October 2019 Accepted: 10 February 2020

Published online: 17 February 2020

\section{References}

1. Harrison JD, et al. What are the unmet supportive care needs of people with cancer? A systematic review. Support Care Cancer. 2009;17(8):1117-28.

2. Husson O, Mols F, Van de Poll-Franse L. The relation between information provision and health-related quality of life, anxiety and depression among cancer survivors: a systematic review. Ann Oncol. 2010;22(4):761-72.

3. Carlson LE, Bultz BD. Efficacy and medical cost offset of psychosocial interventions in cancer care: making the case for economic analyses. Psychooncology. 2004;13(12):837-49.

4. Brown ML, Lipscomb J, Snyder C. The burden of illness of cancer: economic cost and quality of life. Annu Rev Public Health. 2001;22(1):91-113.

5. Au A, et al. Supportive care needs in Hong Kong Chinese women confronting advanced breast cancer. Psycho-Oncology. 2013;22(5):1144-51.

6. Li WW, et al. Interpreting differences in patterns of supportive care needs between patients with breast cancer and patients with colorectal cancer. Psychooncology. 2013;22(4):792-8.

7. Richardson A, et al. Patients' needs assessment in cancer care: a review of assessment tools. Support Care Cancer. 2007;15(10):1125-44.

8. Au A, et al. Validation of the Chinese version of the short-form supportive care needs survey questionnaire (SCNS-SF34-C). Psycho-Oncology. 2011; 20(12):1292-300.

9. Bredart A, et al. Validation of the 34-item supportive care needs survey and 8 -item breast module French versions (SCNS-SF34-Fr and SCNS-BR8-Fr) in breast cancer patients. European journal of cancer care. 2012;21(4):450-9.

10. Doubova SV, et al. Supportive care needs of Mexican adult cancer patients: validation of the Mexican version of the short-form supportive care needs questionnaire (SCNS-SFM). Support Care Cancer. 2015;23(9):2711-9.

11. Li WW, et al. Psychometric assessment of the Chinese version of the supportive care needs survey short-form (SCNS-SF34-C) among Hong Kong and Taiwanese Chinese colorectal cancer patients. PLoS One. 2013;8(10):e75755.

12. Aldridge $L$, et al. Unmet needs in Chinese, Greek, Arabic and Englishspeaking cancer patients in New South Wales. Psychooncology. 2009; 18(Suppl. 2):S117. 
13. Lam WWT, et al. Factors predicting patient satisfaction in women with advanced breast cancer: a prospective study. BMC Cancer. 2018;18(1):162

14. Lam WWT, et al. New insights in symptom assessment: the Chinese versions of the memorial symptom assessment scale short form (MSAS-SF) and the condensed MSAS (CMSAS). J Pain Symptom Manag. 2008;36(6):584-95.

15. Lam CL, Eileen Y, Gandek B. Is the standard SF-12 health survey valid and equivalent for a Chinese population? Qual Life Res. 2005;14(2):539-47.

16. Choi EP, et al. Health-related quality of life of Chinese patients with prostate cancer in comparison to general population and other cancer populations. Support Care Cancer. 2016;24(4):1849-56.

17. Zigmond AS, Snaith RP. The hospital anxiety and depression scale. Acta Psychiatr Scand. 1983;67(6):361-70.

18. Bjelland I, et al. The validity of the hospital anxiety and depression scale: an updated literature review. J Psychosom Res. 2002;52(2):69-77.

19. Lam $\mathrm{CL}_{\text {, et }}$ al. Can the hospital anxiety and depression (HAD) scale be used on Chinese elderly in general practice? Fam Pract. 1995;12(2):149-54.

20. Boyes A, Girgis A, Lecathelinais C. Brief assessment of adult cancer patients' perceived needs: development and validation of the 34-item supportive care needs survey (SCNS-SF34). J Eval Clin Pract. 2009;15(4):602-6.

21. Hu Lt, Bentler PM. Cutoff criteria for fit indexes in covariance structure analysis: Conventional criteria versus new alternatives. Struct Equ Model Multidiscip J. 1999;6(1):1-55.

22. Chin WY, et al. The psychometric properties of the center for epidemiologic studies depression scale in Chinese primary care patients: factor structure, construct validity, reliability, sensitivity and responsiveness. PLoS One. 2015; 10(8):e0135131.

23. Muthén LK, Muthen BO. Mplus User's Guide: Los Angeles, CA: Muthén \& Muthén; 2010.

24. Ware JE Jr, Gandek B. Overview of the SF-36 health survey and the international quality of life assessment (IQOLA) project. J Clin Epidemiol. 1998;51(11):903-12.

25. Jorgensen $\mathrm{ML}$, et al. Unmet supportive care needs in colorectal cancer: differences by age. Support Care Cancer. 2012;20(6):1275-81.

26. Cohen J. Statistical power analysis for the behavioral sciences. 2nd ed. Hillsdale: Erlbaum Associates; 1988.

27. Nunnally JC. Psychometric theory. McGraw-Hill; 1978.

28. Smith DP, et al. Age, health, and education determine supportive care needs of men younger than 70 years with prostate cancer. J Clin Oncol. 2007;25(18):2560-6.

29. Yong HH. Can attitudes of stoicism and cautiousness explain observed agerelated variation in levels of self-rated pain, mood disturbance and functional interference in chronic pain patients? Eur J Pain. 2006;10(5):399.

30. Sanson-Fisher $R$, et al. The unmet supportive care needs of patients with cancer. Cancer. 2000;88(1):226-37.

31. McPherson CJ, Wilson KG, Murray MA. Feeling like a burden: exploring the perspectives of patients at the end of life. Soc Sci Med. 2007;64(2):417-27.

32. Lansbury G. Chronic pain management: a qualitative study of elderly people's preferred coping strategies and barriers to management. Disabil Rehabil. 2000;22(1-2):2-14.

33. Walters $\mathrm{K}$, lliffe $\mathrm{S}$, Orrell M. An exploration of help-seeking behaviour in older people with unmet needs. Fam Pract. 2001;18(3):277-82.

34. Lehmann C, Koch U, Mehnert A. Psychometric properties of the German version of the short-form supportive care needs survey questionnaire (SCNS-SF34-G). Support Care Cancer. 2012;20(10):2415-24.

35. Cossich T, Schofield P, McLachlan S. Validation of the cancer needs questionnaire (CNQ) short-form version in an ambulatory cancer setting Qual Life Res. 2004;13(7):1225-33.

36. Cheung $W Y$, et al. Age and gender differences in symptom intensity and symptom clusters among patients with metastatic cancer. Support Care Cancer. 2011;19(3):417-23.

37. Akechi $\mathrm{T}$, et al. Fatigue and its associated factors in ambulatory cancer patients: a preliminary study. J Pain Symptom Manag. 1999;17(1):42-8.

38. Linden W, et al. Anxiety and depression after cancer diagnosis: prevalence rates by cancer type, gender, and age. J Affect Disord. 2012;141(2-3):343-51.

39. Goldzweig $\mathrm{G}$, et al. How relevant is marital status and gender variables in coping with colorectal cancer? A sample of middle-aged and older cancer survivors. Psychooncology. 2009;18(8):866-74.

40. Greimel ER, Padilla GV, Grant MM. Gender differences in outcomes among patients with cancer. Psychooncology. 1998;7(3):197-206.

41. Lazarus RS, Folkman S. Transactional theory and research on emotions and coping. Eur J Personal. 1987;1(3):141-69.
42. Davis MC, Matthews KA, Twamley EW. Is life more difficult on Mars or Venus? A meta-analytic review of sex differences in major and minor life events. Ann Behav Med. 1999;21(1):83.

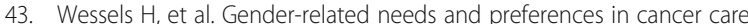
indicate the need for an individualized approach to cancer patients. Oncologist. 2010;15(6):648-55.

44. Churchill GA. A paradigm for developing better measures of marketing constructs. J Mark Res. 1979;16(1):64-73.

45. Lim BT, et al. Information needs of the Chinese community affected by cancer: a systematic review. Psycho-oncology. 2017;26(10):1433-43.

\section{Publisher's Note}

Springer Nature remains neutral with regard to jurisdictional claims in published maps and institutional affiliations.
Ready to submit your research? Choose BMC and benefit from:

- fast, convenient online submission

- thorough peer review by experienced researchers in your field

- rapid publication on acceptance

- support for research data, including large and complex data types

- gold Open Access which fosters wider collaboration and increased citations

- maximum visibility for your research: over $100 \mathrm{M}$ website views per year

At $\mathrm{BMC}$, research is always in progress.

Learn more biomedcentral.com/submissions 